\title{
Tantalum Carbide and Nitride Diffusion Barriers for Cu Metallisation
}

\author{
T. Laurila ${ }^{\text {a) }}$, K. Zeng and J.K. Kivilahti \\ Lab. of Electronics Production Technology,P.O.Box 3000, FIN-02015 HUT, Finland \\ J. Molarius, T. Riekkinen and I.Suni \\ VTT Microelectronics, P.O.Box 1101, FIN-02044 VTT, Finland
}

\begin{abstract}
The reactions in the $\mathrm{Si} / \mathrm{TaC} / \mathrm{Cu}$ and $\mathrm{Si} / \mathrm{Ta}_{2} \mathrm{~N} / \mathrm{Cu}$ metallisation systems were investigated by x-ray diffraction, Rutherford backscattering, scanning electron microscope and the transmission electron microscopy. The results were then combined with the assessed ternary SiTa-C, Ta-C-Cu, Si-Ta-N and Ta-N-Cu phase diagrams. It was found that both barriers ultimately failed due to diffusion of $\mathrm{Cu}$ through the barrier and accompanied formation of $\mathrm{Cu}_{3} \mathrm{Si}$ at temperatures higher than $725^{\circ} \mathrm{C}$. However, in the $\mathrm{TaC}$ barriers the formation of amorphous $\mathrm{TaO}_{\mathrm{x}}$ layer with significant amounts of $\mathrm{C}$ took place at the $\mathrm{TaC} / \mathrm{Cu}$ interface already at $600{ }^{\circ} \mathrm{C}$. Similar behaviour at "low" temperatures was also noted in the $\mathrm{Ta}_{2} \mathrm{~N}$ barriers.
\end{abstract}

Keywords: Phase diagrams; diffusion barriers; copper metallisation, tantalum carbide; tantalum nitride

a) corresponding author,e-mail: Tomi.Laurila@hut.fi 


\section{INTRODUCTION}

Interest in copper for conduction lines and structures has been wide, since it offers many advantages over the currently used $\mathrm{Al}$ based materials. Unfortunately, the interaction between $\mathrm{Si}$ and $\mathrm{Cu}$ is strong and detrimental to the electrical performance of $\mathrm{Si}$ even at temperatures below $200{ }^{\circ} \mathrm{C}[1-3]$. Thus, it is necessary to implement a barrier layer between $\mathrm{Si}$ and $\mathrm{Cu}$. Refractory metals such as tantalum are frequently suggested to be used as barrier layers in $\mathrm{Cu}$ metallised IC's. However, according to our investigations thin elemental Ta barrier layers may not posses sufficient stability when in contact with $\mathrm{Si}$ and $\mathrm{Cu}$ [4]. In order to improve the performance of the barrier layers it is essential to understand the underlying mechanisms leading to the failure. This can be achieved by using a combined thermodynamic and kinetic approach. By utilising this method it was found that the use of binary tantalum compounds like tantalum nitride and tantalum carbide could improve the performance of the barrier layers. The phase relations in the $\mathrm{Si} / \mathrm{TaC} / \mathrm{Cu}$ and $\mathrm{Si} / \mathrm{Ta}_{2} \mathrm{~N} / \mathrm{Cu}$ metallisation systems are examined with the help of the calculated ternary phase diagrams. The information extracted from these diagrams are coupled with the experimental results obtained to reveal the mechanism(s) leading to the failure.

\section{MATERIALS AND METHODS}

The $\mathrm{Cu}, \mathrm{TaC}$ and $\mathrm{Ta}_{2} \mathrm{~N}$ films were sputtered onto cleaned and oxide-stripped (100) oriented n-type Si substrates in a cluster sputtering tool. The base pressure before the deposition was about $3 \times 10^{-5} \mathrm{~Pa}$. Both diffusion barriers were rf-magnetron sputtered, $\mathrm{Ta}_{2} \mathrm{~N}$ in argon/nitrogen gas-mixture from the elemental target whereas $\mathrm{TaC}$ was obtained from the 
compound target in argon atmosphere. Barrier thicknesses were about 10, 50 and $100 \mathrm{~nm}$ for $\mathrm{Ta}_{2} \mathrm{~N}$ and 7, 35, and $70 \mathrm{~nm}$ for $\mathrm{TaC}$, as determined with RBS. The copper films (100 or $400 \mathrm{~nm}$ ) were subsequently sputtered onto $\mathrm{Ta}_{2} \mathrm{~N}$ and $\mathrm{TaC}$ films from the dc-magnetron target without breaking the vacuum. The samples were then annealed in the vacuum of about $10^{-4} \mathrm{~Pa}$ at temperatures from 500 to $800{ }^{\circ} \mathrm{C}$ for $30 \mathrm{~min}$. The reactions in the metallisation schemes were investigated by the sheet resistance measurements, grazing incidence x-ray diffraction (XRD), Rutherford backscattering spectroscopy (RBS), scanning electron microscope (SEM) and the transmission electron microscopy (TEM). The results of the experimental investigations were compared with the assessed phase diagrams. Ternary Si-Ta-C, Ta-C-Cu, Si-Ta-N and Ta-N-Cu phase diagrams were calculated from the assessed binary thermodynamic data [5-10] and compared with the experimental results obtained.

\section{RESULTS AND DISCUSSION}

The sheet resistance measurements vs. temperature of the $\mathrm{Si} / \mathrm{TaC}(70 \mathrm{~nm}) / \mathrm{Cu}(400 \mathrm{~nm})$ samples showed an abrupt rise in the sheet resistance at $775{ }^{\circ} \mathrm{C}$ indicating that a reaction had occurred. The $7 \mathrm{~nm}$ and $35 \mathrm{~nm} \mathrm{TaC}$ layers were stable up to $550{ }^{\circ} \mathrm{C}$ and $650{ }^{\circ} \mathrm{C}$, respectively. The rise in the sheet resistance was accompanied with the loss of shiny copper-like appearance of the sample surface, regardless of the thickness. The SEM micrograph of the surface of the 70 $\mathrm{nm}$ TaC sample annealed at $800{ }^{\circ} \mathrm{C}$ is shown in Fig. 1(a). Large "squares" have formed on the surface (about 20-30 $\mu \mathrm{m}$ in diameter). These "squares" are surrounded by a "flowery" patterned structure, which seems to consist of one phase embedded into another. 
The sheet resistance measurements of the $\mathrm{Si} / \mathrm{Ta}{ }_{2} \mathrm{~N}(100 \mathrm{~nm}) / \mathrm{Cu}(400 \mathrm{~nm})$ showed an abrupt rise in the sheet resistance at $775{ }^{\circ} \mathrm{C}$ and the samples with 10 and $50 \mathrm{~nm} \mathrm{Ta} 2 \mathrm{~N}$ layers were stable up to $625^{\circ} \mathrm{C}$ and $675{ }^{\circ} \mathrm{C}$, respectively. The surfaces of the $\mathrm{Ta}_{2} \mathrm{~N}$ samples maintained their shiny copper-like appearence up to $750{ }^{\circ} \mathrm{C}(100 \mathrm{~nm}), 650{ }^{\circ} \mathrm{C}(50 \mathrm{~nm})$ and $600{ }^{\circ} \mathrm{C}(10 \mathrm{~nm})$. The structure formed on the surface after reaction(s) was very similar to that observed in the $\mathrm{TaC}$ films. The SEM micrograph of the surface structure of the sample with $100 \mathrm{~nm} \mathrm{Ta}_{2} \mathrm{~N}$ barrier annealed at $775^{\circ} \mathrm{C}$ is shown in Fig. 1(b).

The RBS analyses of the as deposited TaC samples showed sharp edges of the elements in the spectra indicating that the layers were clearly discrete at this stage. The spectra from the annealed samples with the $70 \mathrm{~nm}$ thick $\mathrm{TaC}$ layers showed that some reaction(s) had taken place already at $600{ }^{\circ} \mathrm{C}$ (Fig.2). As can be seen, the spectrum has been graded and tantalum has moved towards the surface. This indicates that the $\mathrm{TaC}$ layer has decomposed, which is not expected based on the high thermal stability of $\mathrm{TaC}$ compound. From the spectra taken at higher temperatures, it was very difficult to obtain more information about the reactions taking place, as the surface of the samples did not stay planar (see Figs. 1 (a) and (b)) the interpretation of RBS spectrum was not unambigious.

The RBS analyses of the as deposited $\mathrm{Ta}_{2} \mathrm{~N}$ samples showed also clearly discrete layers before the annealings. The layer thicknessess were about 10, 50 and $100 \mathrm{~nm}$. The spectra from the sample with $100 \mathrm{~nm}$ thick $\mathrm{Ta}_{2} \mathrm{~N}$ layers showed that some reaction(s) took place at $650{ }^{\circ} \mathrm{C}$ (Fig. 3). The temperature was again unexpectedly low as with the $\mathrm{TaC}$ layers. At higher temperatures the spectra further degraded and no additional information could be obtained. 
Hence, the RBS results showed that something unforeseen took place at low temperatures in both metallisation systems.

In order to obtain information about the phase formation during the annealings the XRD analyses were conducted. The results (Fig. 4) from the $\mathrm{Si} / \mathrm{TaC}(70 \mathrm{~nm}) / \mathrm{Cu}(400 \mathrm{~nm})$ samples showed that up to $725^{\circ} \mathrm{C}$ there were only $\mathrm{TaC}$ and $\mathrm{Cu}$ present in the $70 \mathrm{~nm} \mathrm{TaC}$ samples. At 725 ${ }^{\circ} \mathrm{C}$ there were some weak diffractions also from $\mathrm{Ta}_{2} \mathrm{O}_{5}$, showing the presence of oxygen in the annealing ambient and in the metallisation structure. At $750{ }^{\circ} \mathrm{C}$ the formation of $\mathrm{Cu}$-silicide $\left(\mathrm{Cu}_{3} \mathrm{Si}\right)$ took place. However, the analyses showed that $\mathrm{Cu}_{3} \mathrm{Si}$ was not present as its usually cited structure and the peaks were not "stable". At $800{ }^{\circ} \mathrm{C}$, the $\mathrm{TaC}$ and $\mathrm{Cu}$ peaks had disappeared and only $\mathrm{Cu}_{3} \mathrm{Si}$ and $\mathrm{TaSi}_{2}$ peaks were present. According to the phase diagram (Fig. 7(b)) and the mass balance requirement, the formation of $\mathrm{SiC}$ should also have taken place. However, it was not detected in the XRD analysis. Moreover, no indication of reaction(s) at $600{ }^{\circ} \mathrm{C}$ was detected contrary to the RBS results. TaC diffusion barriers showed better performance with increasing thickness. Failure temperature increased from $600(7 \mathrm{~nm})$ to $675(35 \mathrm{~nm})$ to $750{ }^{\circ} \mathrm{C}(70 \mathrm{~nm})$. Despite the different thickness of the films the failure seemed to be induced by $\mathrm{Cu}$ penetration through the $\mathrm{TaC}$ layer and the formation of $\mathrm{Cu}_{3} \mathrm{Si}$.

X-ray diffractograms (Fig. 5) of the annealed $\mathrm{Si} / \mathrm{Ta}_{2} \mathrm{~N}(100 \mathrm{~nm}) / \mathrm{Cu}(400 \mathrm{~nm})$ structures showed unexpected peaks after annealing at $700{ }^{\circ} \mathrm{C}$. Peak positions suggested a hexagonal phase, which was designated as $\operatorname{Ta}_{x} \mathrm{~N}$ phase[12], because we were unable to identify it from standard $\mathrm{x}-$ ray patterns. However, the peaks also fitted quite well to a $\mathrm{Ta}_{\mathrm{x}} \mathrm{O}$ type phase and therefore may be used as an indication from the presence of oxygen in the annealing ambient as well as in the 
metallisation structure itself. However, this must be further verified. The $100 \mathrm{~nm} \operatorname{Ta}_{2} \mathrm{~N}$ diffusion barriers failed by the formation of $\mathrm{Cu}_{3} \mathrm{Si}$ phase at $775{ }^{\circ} \mathrm{C}$. Failure temperature increased from 650 to 725 to $775^{\circ} \mathrm{C}$ as film thickness increased from 10 to 50 to $100 \mathrm{~nm}$ in the same way as in TaC barriers. No reactions between $\mathrm{Ta}_{2} \mathrm{~N}$ and the $\mathrm{Si}$ substrate were detected contrary to the observations in the $\mathrm{TaC}$ system, where $\mathrm{TaSi}_{2}$ formed at higher temperatures. Presently it seems that performance of the $\mathrm{Ta}_{2} \mathrm{~N}$ as well as $\mathrm{TaC}$ barriers is mainly dominated by "defects" in the films. These "defects", e.g. grain boundaries, offer fast diffusion paths for copper atoms, which will then react with silicon by forming copper silicide, $\mathrm{Cu}_{3} \mathrm{Si}$. However, in both systems something unexpected takes place at relatively low temperatures as showed by RBS.

In order to clarify the puzzling RBS results at $600{ }^{\circ} \mathrm{C}$, the cross-sectional TEM specimen was prepared from the $70 \mathrm{~nm}$ TaC sample. The micrograph presented in Fig. 6 shows the presence of an amorphous layer between $\mathrm{TaC}$ and $\mathrm{Cu}$. The amorphous nature of the layer was further verified with HREM investigations and electron diffraction patterns.[11] The layer consisted mainly of Ta with significant amounts of $\mathrm{C}$ and $\mathrm{O}$ as showed by $\mathrm{x}$-ray energy dispersive spectrometry (XEDS) analyses (expected to be metastable $\mathrm{TaO}_{\mathrm{x}}$ layer with $\mathrm{C}$ released in the decomposition of the $\mathrm{TaC}$ layer). As can be seen from Fig. 6, the TaC layer consists of large elongated columnar grains. This should offer suitable short-circuit paths for $\mathrm{Cu}$ diffusion. The fact that significant $\mathrm{Cu}$ diffusion was not detected was attributed to the oxygen rich amorphous layer present at the $\mathrm{TaC} / \mathrm{Cu}$ interface, which formed an additional diffusion barrier to $\mathrm{Cu}$ diffusion. The formation of the layer was induced by diffusion of oxygen to the interface from the annealing environment and also from the films themselves. The stability of $\mathrm{TaO}_{\mathrm{x}}$ is expected to be so high that it was able to decompose the $\mathrm{TaC}$ layer and the formation of the 
observed amorphous interlayer took place. However, this must be verified with detailed thermodynamic description of the Ta-C-O system, which is currently under construction. The carbon found in the amorphous layer is a result of the dissociation of $\mathrm{TaC}$ layer at the $\mathrm{TaC} / \mathrm{Cu}$ interface. Only after suitable high temperature is reached, the amorphous layer is partly or completely crystallised and the diffusion of $\mathrm{Cu}$ will proceed. The observation of the amorphous interlayer formation between $\mathrm{TaC}$ and $\mathrm{Cu}$ gives some indication why the RBS spectrum has degraded already at $600{ }^{\circ} \mathrm{C}$. From the sample annealed at $750{ }^{\circ} \mathrm{C}$ (Fig. 7) one could observe Si$\mathrm{O}, \mathrm{TaO}_{\mathrm{x}}$ along with the very large $\mathrm{Cu}_{3} \mathrm{Si}$ protrusions. This shows that at $750{ }^{\circ} \mathrm{C} \mathrm{Cu}$ atoms have been able to diffuse through the partly crystallised amorphous layer to the $\mathrm{Si} / \mathrm{TaC}$ interface and the formation of $\mathrm{Cu}_{3} \mathrm{Si}$ has taken place. However, no crystalline tantalum silicides were detected and there was still large amount of the amorphous oxide rich layer present. At still higher temperatures $\left(800^{\circ} \mathrm{C}\right) \mathrm{XTEM}$ investigations showed the formation of $\mathrm{TaSi}_{2}$ and $\mathrm{SiC}$, which was expected based on the thermodynamic evaluation of the metallisation system. Similar behaviour is also anticipated to take place in the $\mathrm{Ta}_{2} \mathrm{~N}$ films at $650{ }^{\circ} \mathrm{C}$, since it seems that the annealing ambient as well as the films contained some oxygen also in $\mathrm{Ta}_{2} \mathrm{~N}$ case (see the XRD results) and the RBS results showed similar behaviour in comparision to the $\mathrm{TaC}$ films. Unfortunately detailed TEM results are not yet available.

The phase relationships in the Si-Ta-C, Si-Ta-N, and in the Ta-C-Cu, Ta-N-Cu phase diagrams are very similar. Figure 8 (a) shows the evaluated isothermal section of the ternary Ta$\mathrm{C}-\mathrm{Cu}$ phase diagram. It can be seen that $\mathrm{Cu}$ is in equilibrium with both $\mathrm{TaC}$ and $\mathrm{Ta}_{2} \mathrm{C}$. Thus, the reactions at the interface $\mathrm{Cu} / \mathrm{TaC}$ do not have driving force because the interface is already in local thermodynamic equilibrium. Nevertheless, the driving force for copper diffusion through 
barrier towards silicon is expected to be substantial, since copper has a very high affinity towards silicon. Figure 8 (b) shows the isothermal section of the calculated Ta-Si-C ternary phase diagram. There are two important issues, which have to be carefully considered in the calculations due to the lack of reliable experimental information. However, they have been discussed previously elsewhere [13] and are not repeated here. It can be seen that at the $\mathrm{Si} / \mathrm{TaC}$ interface there exist a driving force for reaction between the substrate and the $\mathrm{TaC}$ layer, since there is no TaC-Si equilibrium in the ternary phase diagram(Fig. 8(b)). In fact, reactivity of this interface was manifested by the experimentally observed formation of $\mathrm{TaSi}_{2}$ and $\mathrm{SiC}$ at $800{ }^{\circ} \mathrm{C}$. Figure 9 (a) shows the isothermal section from the Ta-N-Cu diagram. The same thermodynamic considerations about the barrier/Cu interface, as in the carbide case, are also valid here. Figure 9 (b) shows the isothermal section from the $\mathrm{Si}-\mathrm{Ta}-\mathrm{N}$ phase diagram. Again the similarity is evident. Hence, the systems resemble each other very closely. As expected on the basis of the thermodynamic properties of the metallisation systems, the failure mechanisms were found to be of similar kind. No reactions between $\mathrm{Si}$ and $\mathrm{Ta}_{2} \mathrm{~N}$ were detected in this investigation up to 775 ${ }^{\circ} \mathrm{C}$ and the failure occurred by the formation of $\mathrm{Cu}_{3} \mathrm{Si}$, thus indicating considerably stability of the $\mathrm{Si} / \mathrm{Ta}_{2} \mathrm{~N}$ interface.

\section{CONCLUSIONS}

The interfacial reactions in the $\mathrm{Si} / \mathrm{TaC} / \mathrm{Cu}$ and $\mathrm{Si} / \mathrm{Ta}_{2} \mathrm{~N} / \mathrm{Cu}$ systems were investigated. The diffusion of $\mathrm{Cu}$ through the barrier and the accompanied formation of $\mathrm{Cu}_{3} \mathrm{Si}$ ultimately caused the failure of both of the barrier layers. The stabilities of the $\mathrm{TaC}$ and $\mathrm{Ta}_{2} \mathrm{~N}$ layers were found to be reasonably high and of similar magnitude. However, both systems exhibited similar kind of intriguing reaction at low temperatures $\left(600{ }^{\circ} \mathrm{C}\right.$ for $\mathrm{TaC}$ and $650{ }^{\circ} \mathrm{C}$ for $\left.\mathrm{Ta}_{2} \mathrm{~N}\right)$. In the 
$\mathrm{TaC}$ case the reaction was found to be an amorphous $\mathrm{TaO}_{\mathrm{x}}$ layer formation at the $\mathrm{TaC} / \mathrm{Cu}$ interface. Formation of similar kind of layer is also expected to take place in the $\mathrm{Si} / \mathrm{Ta} \mathrm{a}_{2} \mathrm{~N} / \mathrm{Cu}$ system. The observed similarities in the behaviour of the carbide and nitride films can be understood with the help of the corresponding evaluated $\mathrm{Si}-\mathrm{Ta}-\mathrm{C}, \mathrm{Si}-\mathrm{Ta}-\mathrm{N}, \mathrm{Ta}-\mathrm{C}-\mathrm{Cu}$ and Ta-N$\mathrm{Cu}$ ternary phase diagrams, which show almost identical phase relationships.

\section{ACKNOWLEDGEMENTS}

Authors greatly acknowledge J. Saarilahti and A. Nurmela from the VTT Microelectronics for help in the RBS analyses. The work was financially supported by the Academy of Finland. 
References:

[1] A.A. Istratov and E.R. Weber, Electrical Properties and Recombination Activity of Copper, Nickel and Cobolt in Silicon, Appl. Phys. A, 66, (1998) 123-136.

[2] S.P. Murarka, Advanced Materials for Future Interconnections of the Future Need and Strategy, Microelectronic Engineering, 37/38, (1997) 29-37.

[3] C-A. Chang, Formation of Copper Silicides from $\mathrm{Cu}(100) / \mathrm{Si}(100)$ and Cu(111)/Si(111) Structures, J. Appl. Phys. 67, (1990), 566-569.

[4] T.Laurila, K. Zeng, J.K. Kivilahti, J. Molarius and I. Suni, Failure Mechanism of Ta Diffusion Barrier Between Cu and Si, J. Appl. Phys., 88, (2000) 3377-3384.

[5] J. Lacaze and B. Sundman, An Assessment of the Fe-C-Si System, Metall. Trans. A, 22, (1991), 2211-2223.

[6] K. Frisk and A. F. Guillermet, Gibbs Energy Coupling of the Phase Diagram and Thermochemistry in the Tantalum-Carbon System, J. Alloys Compd., 238, (1996),167-178.

[7] L. Chandra Sekaran, Cu-Fe-P-C, Report , Data in Thermo-Calc, (1987).

[8] K. Frisk, A Thermodynamic Evaluation of the Fe-Cu-C-N System, Report IM-2929, Swedish Institute for Metals Research, Stockholm.

[9] M. Hillert, S. Jonsson, and B. Sundman, Thermodynamic Calculation of the Si-N-O System, Z. Metallkde., 83, (1992), 648-654.

[10] K. Frisk, Analysis of the Phase Diagram and Thermochemistry in the Ta-N and the Ta-C-N Systems, J. Alloys Compd., 278, (1998), 216-226.

[11] T.Laurila, K. Zeng, J.K. Kivilahti, J. Molarius and I. Suni, TaC as a Diffusion Barrier Between $\mathrm{Cu}$ and $\mathrm{Si}$, to be submitted. 
[12] J. Molarius, T. Riekkinen, I. Suni, T. Laurila, K.Zeng and J.K. Kivilahti, Reactively Sputtered $\mathrm{Ta}_{2} \mathrm{~N}$ and TaN Diffusion Barriers for Copper Metallization, Advanced Metallization Conference 2000 (AMC), San Diego, CA, 3-5 Oct., (2000), 137-138.

[13] T.Laurila, K. Zeng, J.K. Kivilahti, J. Molarius and I. Suni, Reliability of Tantalum Based Diffusion Barriers between Copper and Silicon, 2000 MRS Spring Meeting (Materials Research Society), San Francisco CA, 24-28 April, v612, (2000), 97. 


\section{FIGURE CAPTIONS}

FIG.1. (a) SEM micrograph from the surface of the $\mathrm{Si} / \mathrm{TaC}(70 \mathrm{~nm}) / \mathrm{Cu}(400 \mathrm{~nm})$ sample annealed at $800{ }^{\circ} \mathrm{C}$ for $30 \mathrm{~min}$ and (b) SEM micrograph from the surface of the $\mathrm{Si} / \mathrm{Ta}_{2} \mathrm{~N}(100 \mathrm{~nm}) /$ $\mathrm{Cu}(400 \mathrm{~nm})$ sample annealed at $775^{\circ} \mathrm{C}$ for $30 \mathrm{~min}$.

FIG.2. RBS spectra $\left(2.0 \mathrm{MeV} 4 \mathrm{He}^{+}, \theta=170^{\circ}\right)$ from the $\mathrm{Si} / \mathrm{TaC}(70 \mathrm{~nm}) / \mathrm{Cu}(400 \mathrm{~nm})$ samples annealed at different temperatures for $30 \mathrm{~min}$. Vertical arrows represent surface scattering energies.

FIG.3. RBS spectra $\left(2.0 \mathrm{MeV} 4 \mathrm{He}^{+}, \theta=170^{\circ}\right)$ from the $\mathrm{Si} / \mathrm{Ta}_{2} \mathrm{~N}(100 \mathrm{~nm}) / \mathrm{Cu}(400 \mathrm{~nm})$ samples annealed at different temperatures for $30 \mathrm{~min}$. Vertical arrows represent surface scattering energies.

FIG.4. XRD spectra from the $\mathrm{Si} / \mathrm{TaC}(70 \mathrm{~nm}) / \mathrm{Cu}(400 \mathrm{~nm})$ samples annealed at different temperatures.

FIG. 5. XRD spectra from the $\mathrm{Si} / \mathrm{Ta}_{2} \mathrm{~N}(100 \mathrm{~nm}) / \mathrm{Cu}(400 \mathrm{~nm})$ samples annealed at different temperatures.

FIG.6. Bright field cross-sectional TEM micrograph from the $\mathrm{Si} / \mathrm{TaC}(70 \mathrm{~nm}) / \mathrm{Cu}(400 \mathrm{~nm})$ sample annealed at $600{ }^{\circ} \mathrm{C}$ for $30 \mathrm{~min}$.

FIG.7. Bright field cross-sectional TEM micrograph from the $\mathrm{Si} / \mathrm{TaC}(70 \mathrm{~nm}) / \mathrm{Cu}(400 \mathrm{~nm})$ sample annealed at $750{ }^{\circ} \mathrm{C}$ for $30 \mathrm{~min}$. Original surface is on the top of the figure.

FIG.8. (a) Isothermal section at $700{ }^{\circ} \mathrm{C}$ from the ternary Ta-C-Cu phase diagram (b) isothermal section at $700{ }^{\circ} \mathrm{C}$ from the ternary Si-Ta-C phase diagram.

FIG.9. (a) Isothermal section at $700{ }^{\circ} \mathrm{C}$ from the ternary Ta-N-Cu phase diagram, (b) isothermal section at $700{ }^{\circ} \mathrm{C}$ from the ternary Si-Ta-N phase diagram. 


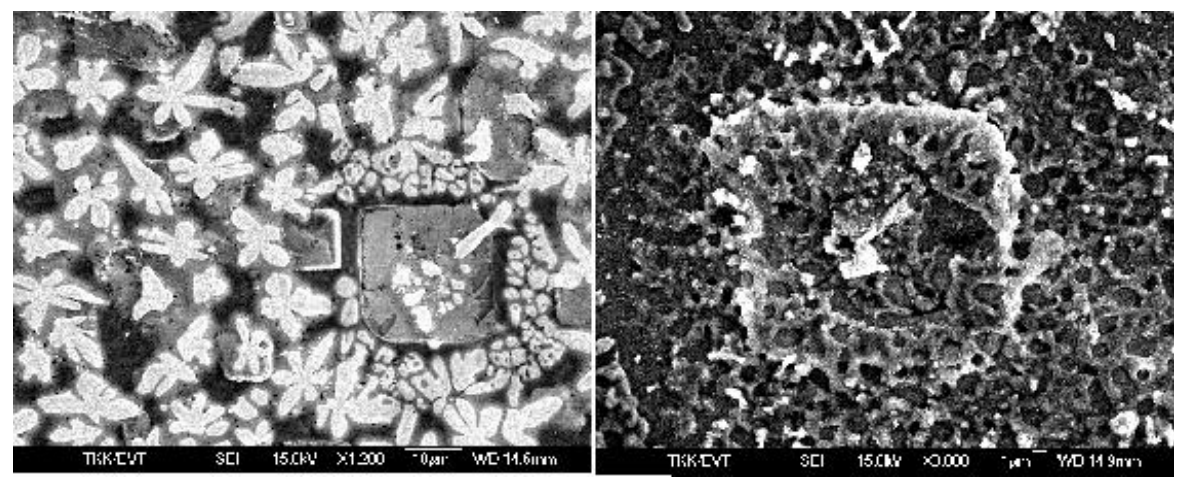

(a)

(b)

Fig. 1 


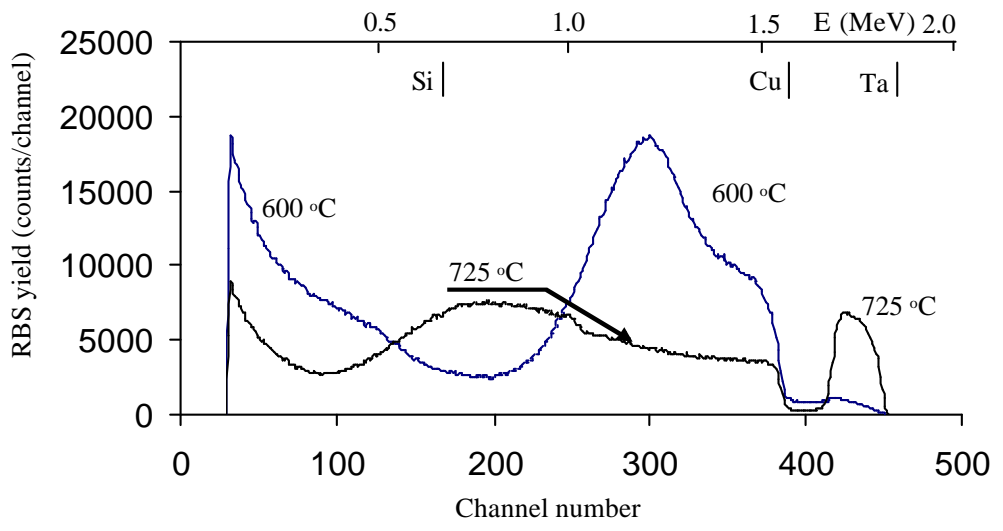

Fig. 2 


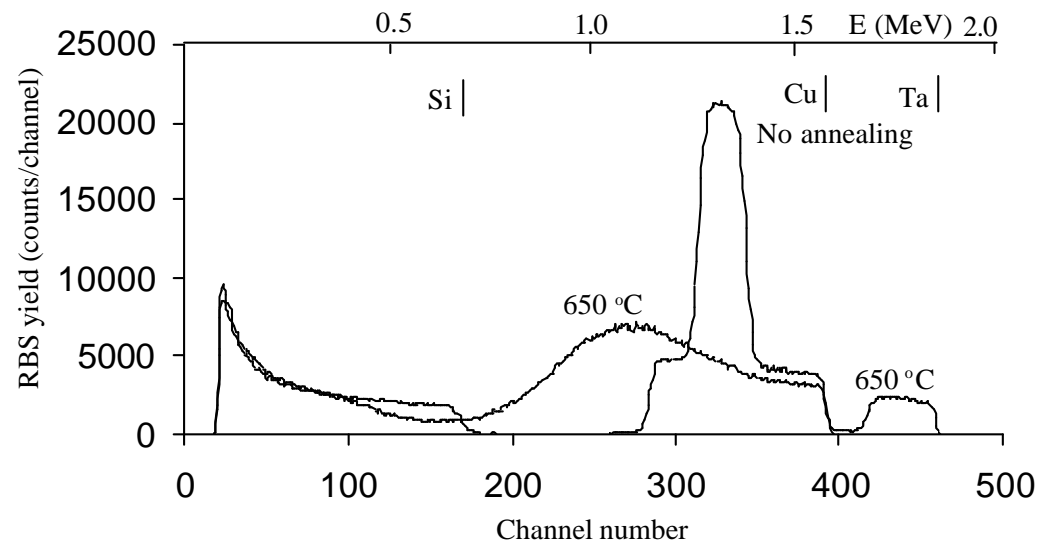

Fig. 3 


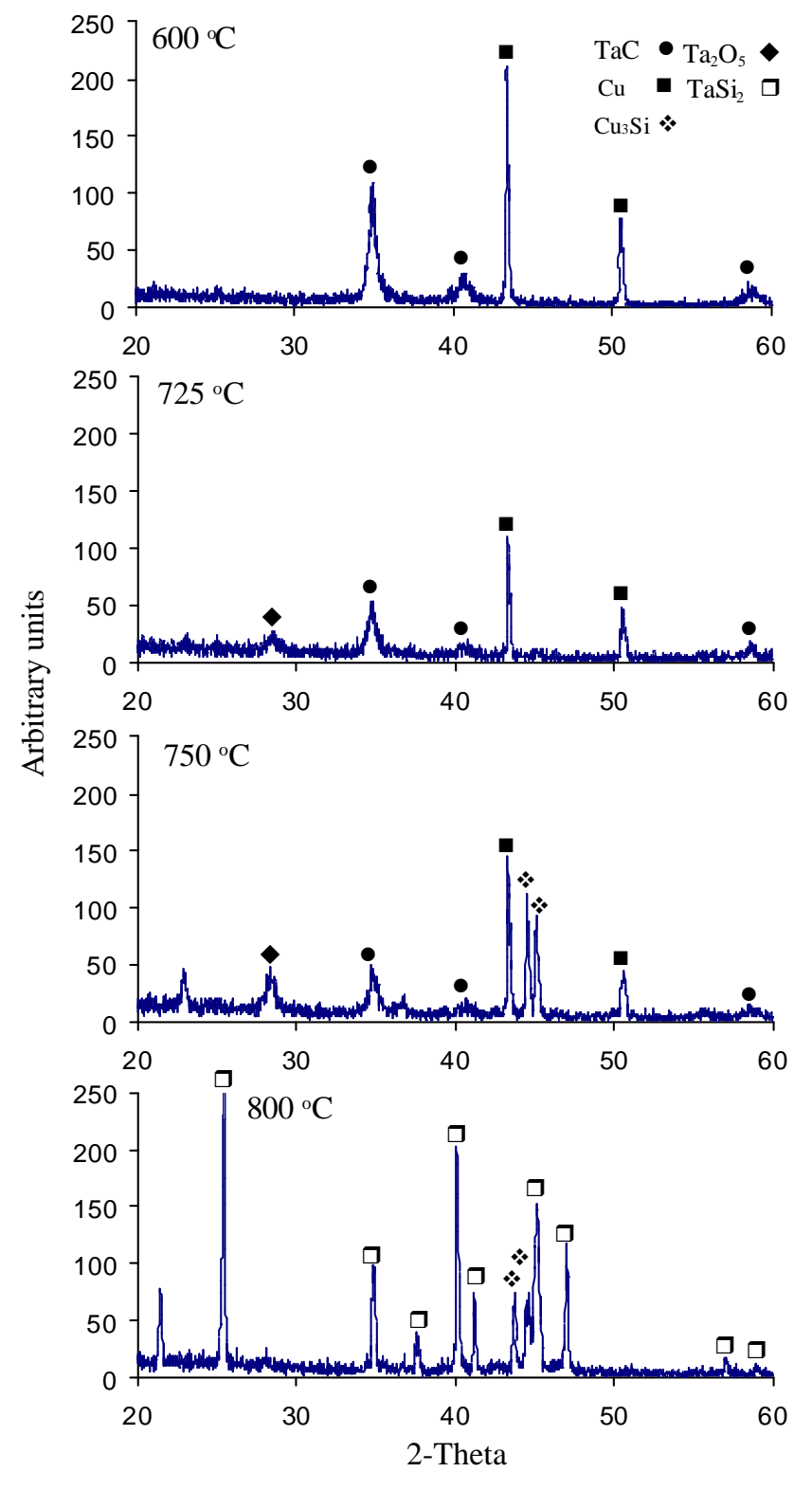

Fig. 4 


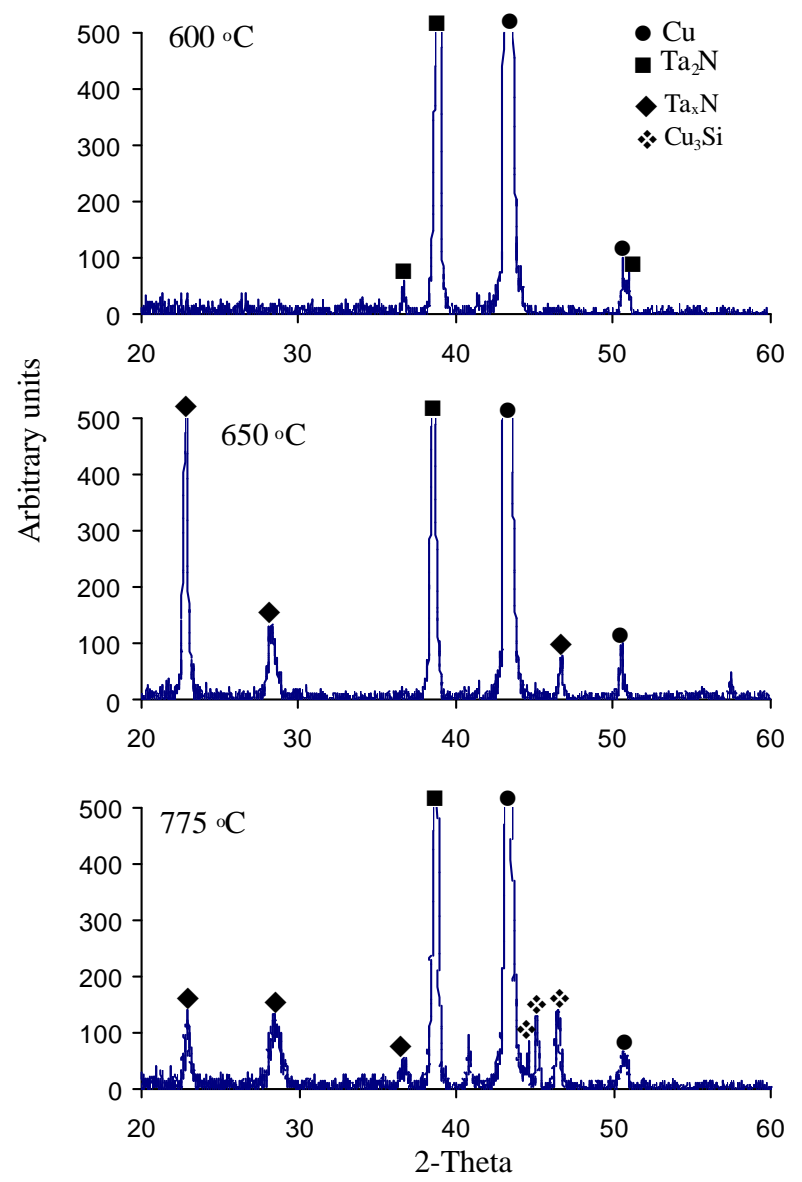

Fig. 5 


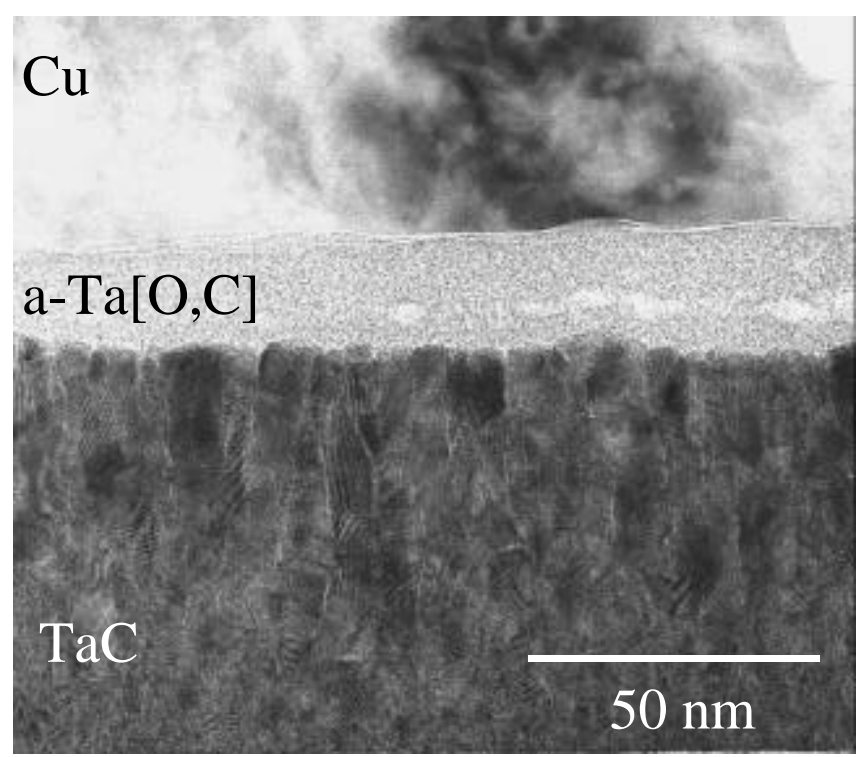

Fig. 6 


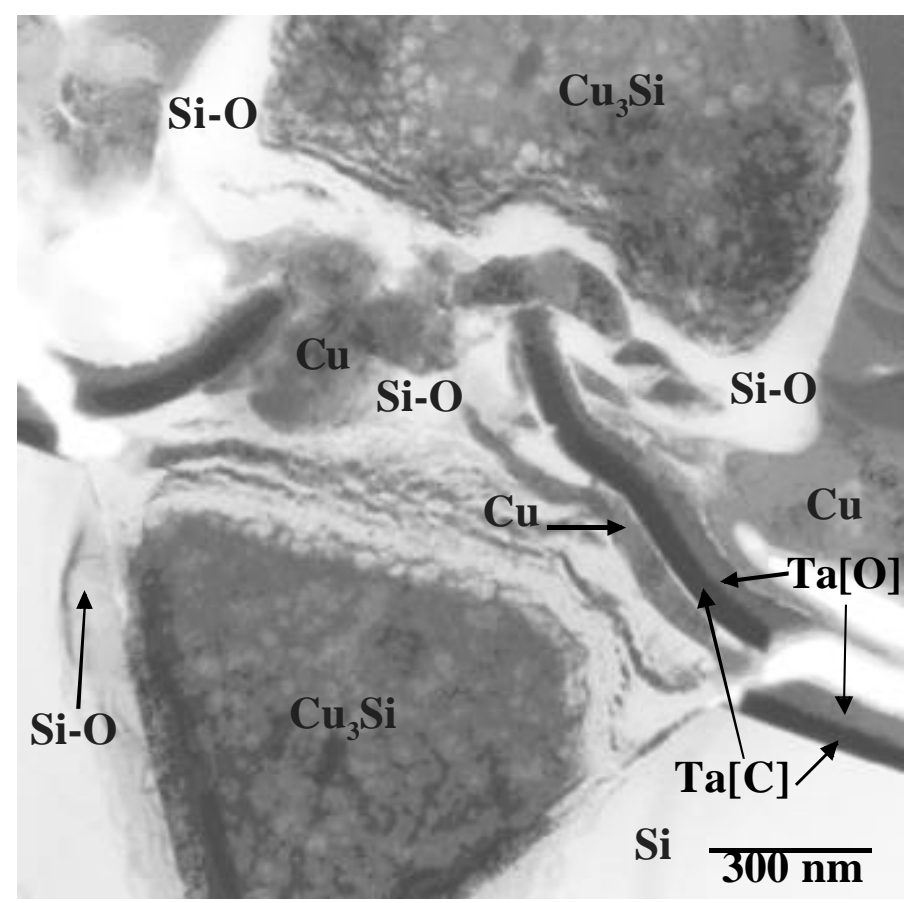

Fig. 7 

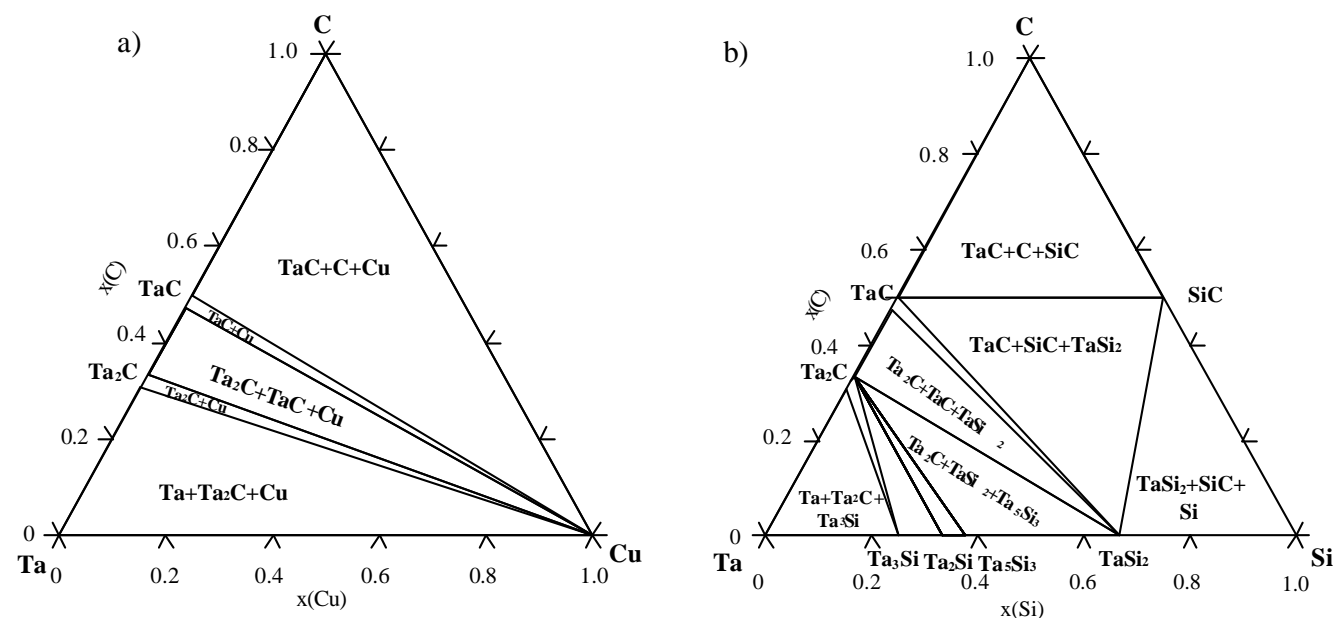

Fig. 8 


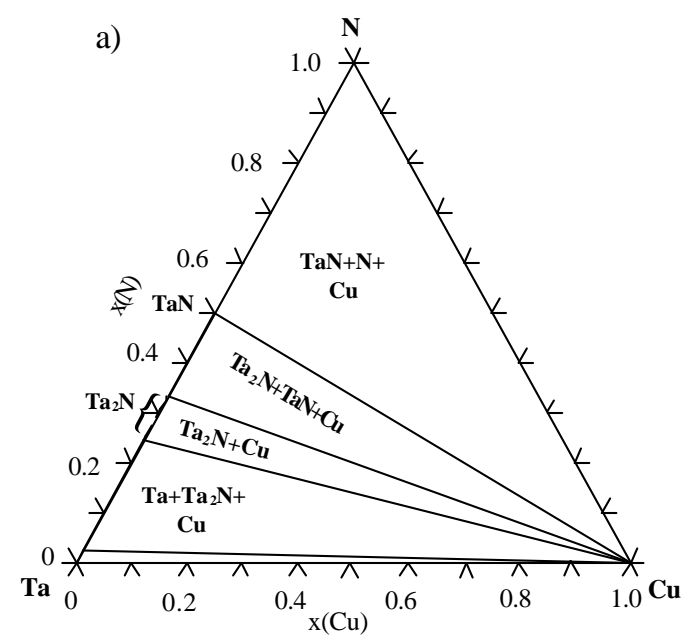

b)

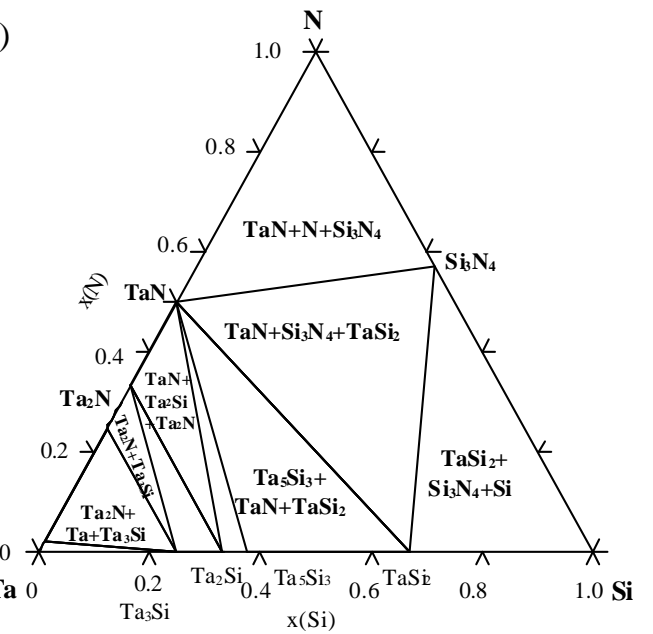

Fig. 9 